\title{
Hormonal Contraceptive Use Related to Menopausal Age
}

\section{Destri Safhira Siahaan" ${ }^{1}$, Adek Amansyah2*, Irza Haicha Pratama²}

${ }^{1}$ Undergraduate Student of Medical Education, Faculty of Medicine, Universitas Prima Indonesia, Medan, Indonesia

${ }^{2}$ Faculty of Medicine, Universitas Prima Indonesia, Medan, Indonesia

\section{A R T I C L E I N F O}

\section{Keywords:}

Family planning

Hormonal contraceptive

Menopausal age

Menarche

\section{*Corresponding author:}

Adek Amansyah

E-mail address:

\section{adek_amansyah@yahoo.com}

All authors have reviewed and approved the final version of the manuscript.

https://doi.org/10.37275/AMCR.v2i4.155

\section{A B S T R A C T}

The change in the pattern and timing of menopause is an exciting and exploratory phenomenon that requires more detailed research to be carried out using hormonal contraception. This study was aimed to explore the relationship between hormonal contraceptive use and menopausal age. This study used a cross-sectional design. The study was conducted at Royal Prima General Hospital Medan from May to August 2021. A total of 68 research subjects participated in this study with the following inclusion criteria: menopausal women, aged 50-60 years, using hormonal contraceptives (pills, injections, implants), able to remember history previous contraceptive use. This study uses primary data obtained directly from guided interviews with respondents. Participants were dominated by $\geq 55$ years old women with 57 people (83.81\%), 62 Muslims $(91.2 \%)$, menarche age $>13$ years as many as 28 people $(41.2 \%)$. The number of children 2-4 were 32 people $(47.1 \%)$ with an average menopause age of 51.93 and the smallest for 1 was 8 people $(11.8 \%)$ with an average menopause age of 50.37 . There were 49 users of hormonal contraception (72.1\%) and 48 people $(70.6 \%)$. In conclusion, we found that the use of hormonal contraceptives is significantly related to menopausal age.

\section{Introduction}

Menopause is a change in a woman when her menstrual period has stopped. A woman has reached menopause when she no longer has menstruation for 12 months. ${ }^{1}$ By 2030, the number of women worldwide who enter menopause is estimated to reach 1.2 billion people. In Indonesia, in 2025, there will be 60 million menopausal women. In 2016 Indonesia reached 14 million menopausal women, or $7.4 \%$ of the total population. ${ }^{2}$ The average age of menopause is 51.4 years, but $10 \%$ of women stop menstruating at the age of 40 years, and $5 \%$ do not stop menstruating until the age of 60 years. $^{3}$ A woman who has entered menopause, estrogen and progesterone levels will decrease rapidly because the ovaries have stopped responding to follicle-stimulating hormone (FSH) and luteinizing hormone (LH), which are produced in the pituitary gland in the brain. Here actually, the brain has been trying to secrete more FSH and LH so that the ovaries can function correctly. However, this will have no effect because both ovaries cannot function normally.

Several factors influence the occurrence of menopause in women, one of which is physical factors, anxiety, age at first menstruation (menarche), age at delivery, smoking, socioeconomic, cultural, and environmental factors, diabetes, nutritional status, and stress, and the use of contraception. 5 The use of contraceptives, especially hormonal contraceptives, namely pills, injections, and implants, has a 
bothersome effect on women because the hormones present in these contraceptives suppress the function of the ovaries. The content of the hormones estrogen and progesterone from hormonal contraceptives in a woman's body is related to the age of a woman who enters menopause, where the work of these hormones suppresses the ovaries so that eggs are not produced, this can affect a person's delay in entering menopause compared to women who do not use hormonal contraception. ${ }^{6}$ In 2017, the use of hormonal contraception in Indonesia was 22,226,419 (94.15\%) of the total $23,606,218$ active family planning participants. ${ }^{7}$

A study showed that $14.7 \%$ experienced menopause at the age of 52 years, which according to the theory of menopause, occurred at the age of 45-50 years with usual clinical features of menstruation stops. ${ }^{8}$ Another study showed that as many as $16.7 \%$ of women experienced menopause at 55 years. 9 This change in the pattern and timing of menopause is an exciting and exploratory phenomenon that requires more detailed research to be carried out using hormonal contraception.

\section{Methods}

This study used a cross-sectional design. The study was conducted at Royal Prima General Hospital Medan from May to August 2021. A total of 68 research subjects participated in this study with the following inclusion criteria: menopausal women, aged 50-60 years, using hormonal contraceptives (pills, injections, implants), able to remember history previous contraceptive use. This study uses primary data obtained directly from guided interviews with respondents.

Interviews were conducted to obtain data on age, religion, age at menarche, number of children, use of hormonal contraception, and age of menopause. Any data obtained from the interview process is entered into a case report form. The data was then processed with the help of SPSS version 25 software. Univariate analysis was performed to display the frequency distribution of each variable of age, religion, age at menarche, number of children, use of hormonal contraception, and age of menopause. Furthermore, bivariate analysis was conducted to see the relationship between hormonal contraception and menopause age, using chi-square analysis ( $\mathrm{p}$-value <0.05). If the probability value is less than 0.05 , there is a significant difference between the test variables.

\section{Results}

Table 1 shows the age frequency distribution with 68 respondents dominated by 55 years as many as 57 people (83.8\%), and 11 people aged <55 years (16.2\%). The distribution of the frequency of religion with as many as 68 respondents and dominated by Islam as many as 62 people (91.2\%) and for Christians as many as 6 people (8.8\%). The frequency distribution of Menarche Age with respondents as many as 68 respondents and dominated by the most are $>13$ years as many as 28 people (41.2\%), and the smallest for $<12$ years as many as 18 people (26.9\%). The frequency distribution of the number of children with respondents as many as 68 respondents and dominated by 2-4 as many as 32 people (47.1\%) with an average age of menopause 51.93 and the smallest for 1 as many as 8 people $(11.8 \%)$ with an average age of menopause 50.37. The distribution of the frequency of hormonal contraception with respondents as many as 68 respondents and dominated by the majority who answered Yes as many as 49 people (72.1\%), and the smallest for those who answered No as many as 19 people (27.9\%). Menopause frequency distribution with respondents as many as 68 respondents and respondents with normal menopause as many as 20 people $(29.4 \%)$, and late menopause as many as 48 people $(70.6 \%)$. 
Table 1. Frequency distribution of research variables

\begin{tabular}{|l|l|l|}
\hline \multicolumn{2}{|l|}{ Variable } & \multicolumn{1}{|c|}{ Frequency (percent) } \\
\hline \multirow{2}{*}{ Age } & $<55$ years & $11(16.2)$ \\
& $\geq 55$ years and & $57(83.8)$ \\
\hline \multirow{2}{*}{ Religion } & Islamic & $62(91.2)$ \\
& Christian & $6(8.8)$ \\
\hline \multirow{2}{*}{ Menarche age } & $<12$ Years & $18(26.9)$ \\
& $12-13$ Years & $22(32.4)$ \\
& $>13$ Years & $28(41.2)$ \\
\hline \multirow{2}{*}{ Number of Children } & 1 person & $8(11.8)$, Mean $=50.37$ \\
& $2-4$ people & $32(47.1)$, Mean $=51.93$ \\
& $\geq 5$ people & $28(41.7)$, Mean $=53.64$ \\
\hline \multirow{2}{*}{ Hormonal contraception } & No & $19(27.9)$ \\
& Yes & $49(72.1)$ \\
\hline Menopause & Normal & $20(29.4)$ \\
& Late & $48(70.6)$ \\
\hline
\end{tabular}

Tables 2 and 3 show the results of the chi square test using the chi square-countinuity correction test, the $\mathrm{p}$ value $<0.05$ so it can be concluded that the use of hormonal contraception is significantly related to the age of menopause and is significantly related to the age of menarche.

Table 2. Correlation between the use of hormonal contraceptives with menopausal age

\begin{tabular}{|c|c|c|c|}
\hline \multirow{2}{*}{$\begin{array}{c}|c| \\
\text { Hormonal } \\
\text { Contraception }\end{array}$} & Normal & Late & \multirow{2}{*}{ p* $^{*}$} \\
\cline { 2 - 4 } & $14(73.7 \%)$ & $5(26.3 \%)$ & 0.005 \\
\hline No & $6(12.2 \%)$ & $43(87.8 \%)$ & \\
\hline Yes & & \\
\hline
\end{tabular}

${ }^{*} \mathrm{p}<0.05$, chi-square (continuity correction)

Table 3. Relationship between menarche age and menopause

\begin{tabular}{|c|c|c|c|}
\hline \multirow{2}{*}{ Age Menarche } & \multicolumn{2}{|c|}{ Age Menopause } & \multirow{2}{*}{$\mathbf{p}^{*}$} \\
\cline { 2 - 4 } & Normal & $17(94.4 \%)$ & 0.005 \\
\hline$<12$ Years & $1(5.6 \%)$ & $19(86.4 \%)$ & \\
\hline $12-13$ Years & $3(13.6 \%)$ & $12(42.9 \%)$ & \\
\hline$>13$ Years & $16(57.1 \%)$ & & \\
\hline
\end{tabular}

${ }^{*} \mathrm{p}<0.05$, chi square (continuity correction)

\section{Discussion}

This study is following other studies; it can be concluded that respondents who use contraceptives who experience menopause age 50 years are 34 respondents $(31.4 \%)$, and those who experience menopause age below 50 years are 11 respondents (13.6\%), while respondents who did not use contraception who experienced menopause age at the age of 50 years were three respondents (5.6\%), and those who experienced menopause age below 50 years old were five respondents (2.4\%). After the chi-square 
test, the p-value is 0.045 with a level of $5 \%(0.05)$. Based on these results, the p-value is 0.045; this means that it is significant or there is a relationship between the use of contraceptives and the age of menopause. 10

Other studies also show that most of the respondents experienced physical changes using a history of hormonal contraceptives $(\mathrm{KB})$ as many as 64 (94.1\%), a small proportion of respondents did not suffer from physical changes using an account of nonhormonal contraceptives (KB) as many as 6 (66, 7\%). After tabulation, analysis was carried out using Chisquare and obtained a P-value of $0.000<0.05$, so HO was rejected. So, there is a relationship history of using contraceptives (KB) with physical changes at menopause in Sluke village, Sluke district, Rembang regency in $2016 .{ }^{11}$

Contraception is a way to prevent the occurrence of conception and use of contraception, especially hormonal contraception; in women who use hormonal contraception, it will be longer or older to enter menopause. This can happen because the way contraception works suppress the function of the ovaries so that they cannot produce eggs. Most hormonal contraceptives suppress the production and secretion of gonadotropins, hormones included in the gonadotropins, namely FSH (follicle-stimulating hormone) and LH (luteinizing hormone) hormones play a role in the maturation and release of ovarian follicles ${ }^{12}$.

Administration of the hormone estrogen or progesterone in a specific concentration and time can suppress the production and secretion of gonadotropins through a positive-negative feedback mechanism. Administration of the hormones estrogen and progesterone through hormonal contraception will cause the concentration of the two steroid hormones to increase until it reaches a specific concentration that can stimulate the anterior pituitary to stop the production and secretion of $\mathrm{FSH}$ and $\mathrm{LH}$. When the production and secretion of gonadotropins are inhibited, the follicle maturation process will be inhibited, and ovulation will not occur, causing menstruation that does not produce eggs and affects female fertility, making a person late for menopause.

Family planning is a couple effort to measure the number and distance of children they want. The business in question includes contraception or prevention of pregnancy and family planning. The basic principle of the contraceptive method is to prevent male sperm from reaching and fertilizing a woman's egg or preventing a fertilized egg from implanting (attaching) and developing in the uterus. The purpose of implementing the family planning program is to form a small family following the socio-economic strength of a family by regulating the birth of children to obtain a happy and prosperous family that can meet their needs. Another purpose of the family planning program is to reduce the birth rate significantly. To achieve this goal, a policy is categorized into three phases (spacing, postponing, and stopping); the policy aims to save mothers and children from giving birth at a young age, birth spacing who are too close and give birth at an old age. 13

This study has limitations that may affect the quality of research results. The influencing factors in this study include the possibility of the number of samples used in only one hospital. This is due to time, and cost so that not all batches were selected and did not meet the researcher's criteria. Although there are assumptions that underlie the use of questionnaires as a data collection technique, namely, respondents provide answers according to actual conditions; the reality is that it is difficult to control.

\section{Conclusion}

The use of hormonal contraceptives is significantly related to menopausal age.

\section{References}

1. Santoro N, Epperson CN, Mathews S. Menopausal symptoms and their management. Endocrinol Metab Clin North Am. 2015; 44(3): 
497-515.

2. Octavani $\mathrm{C}$, Meiyanti $\mathrm{M}$. The relationship of menopause with depression among women over 50 years old. J Ked Kes Indo. 2019; 10(1).

3. Hestiantoro A, Jasirwan SO, Wiwie M, Shadrina A, Ibrahim N, Astuti BPK. Low estradiol levels escalate menopausal symptoms leading to mild cognitive impairment in postmenopausal women. Med J Indo. 2019; 28(1): 2447.

4. Ceylan B, Ozerdogan N. Factors affecting age of onset of menopause and determination of quality of life in menopause. Turk J Obstet Gynecol. 2015; 12(1): 43-49.

5. Sharifi K, Tagharrobi Z, Sooki Z. Quality of life among Iranian postmenopausal women: A systematic review and meta-analysis. Galen Med J. 2020; 9: e1649.

6. Bustami M, Matalka KZ, Elyyan Y, Hussein N, Hussein N, et al. Age of natural menopause among Jordanian women and factors related to premature and early menopause. Risk Manag Healthc Policy. 2021; 14: 199-207.

7. Idris $H$. Factors affecting the use of contraceptive in Indonesia: Analysis from the National Socioeconomic Survei (Susenas).
Kesmas: J Kes Mas. 2019; 15(1).

8. Kumari A, Paniraghi A, Roy A, Panda J. Impaired quality of life and its determinants among postmenopausal women in slum communities in Bhubaneswar, India. J Midlife Health. 2020; 11(3): 149-55.

9. Chou MF, Wun YT, Pang SM. Menopausal symptoms and the menopausal rating scale among midlife Chinese women in Macau, China. Women Health. 2014; 54(2): 115-26.

10. Gafar A, Suza DE, Efendi F, Has EMM, Pramono AP, et al. Determinants of contraceptive use among married women in Indonesia. F1000Res.2020; 9:193.

11. Ramania NAC. Determining factors related to the type of contraceptives in Indonesia. $\mathrm{J}$ Biometrika Kependudukan. 2020; 9(2):112-20.

12. Kusmiyati Y, Prasistyarni A, Wahyuningsih HP, Widyasih H, Estiningtyas Q, et al. Duration of hormonal contraception and risk of cervical cancer. Kesmas: J Kes Mas Nasional. 2019; 14(1).

13. Winarni E, Dawam M. Family planning information, education and communication with contraceptive use. Kesmas: J Kes Mas Nasional.2016; 11(2). 